\title{
11th International Conference on Pattern Recognition
}

\section{August 31 - September 3, 1992 \\ Opening address}

\author{
E.S. Gelsema \\ Erasmus University, Rotterdam, Netherlands
}

Ladies and gentlemen,

It is a great honour and indeed a great pleasure for me, on behalf of the Organizing Committee, to welcome you to this 11 th International Conference on Pattern Recognition. We are happy that, through our publicity and through our scientific program, we have attracted so many participants. This shows very clearly that a broad conference on all aspects of pattern recognition and image processing remains attractive to the scientific community.

We especially welcome three persons, two of whom I cannot mention by name yet. They are the recipients of two awards: The very first recipient of the award for the best industry-related paper and the third recipient of the now well-established King-Sun $\mathrm{Fu}$ award ${ }^{1}$. The presentation of these

\footnotetext{
1 The contribution selected as the best industry-related paper was: $Q$. Zheng and $R$. Chellappa, A computational vision ap. proach to image registration, Proceedings Vol. I, 193-197. Later in the plenary opening session, the award was presented to $\mathrm{R}$. Chellappa.

The recipient of the King-Sun Fu award was L.N. Kanal. His award address delivered during the opening session appears in this conference review.

A third award was presented during the banquet of the conference: The award for the best paper in Pattern Recognition Letters Volumes 11 and 12 . The winning paper for this award issued by Elsevier Science Publishers (North-Holland) was: M. Bister, J. Cornelis and A. Rosenfeld, A critical review of pyramid segmentation algorithms, Pattern Recognition Lett. $11,605-617(1990)$.
}

awards and the keynote speech by the recipient of the King-Sun Fu award are the main ingredients of this plenary session. Both awards are issued by the International Association for Pattern Recognition (IAPR). This Association, as you know, sponsors the ICPR series of conferences. ICPR-1 was held in 1973 in Washington DC. We are proud to be the 11 th in this prestigious series. We also extend, therefore, a special welcome to the President of the IAPR, Professor Michael Duff.

Like the previous conference in Atlantic City, this conference has been organized as an umbrella over four specialty conferences. This formula allows the conference organizers to specifically focus on promising areas as they develop. A potential problem surfaced in Atlantic City, when it became known that the Computer Vision community was planning to hold two other conferences at about this time. One more conference on this topic in the form of one of our specialty conferences seemed to be somewhat overdone. One possible solution was to merge two of the potentially three computer vision conferences. We seriously explored these possibilities with the other conference organizers. Although no agreement was reached on that point, some slight adjustments in time schedule were implemented. This enabled us to stick with Computer Vision as one of our tracks.

There has been some controversy over the paper selection procedure that we have adopted. At an early stage we decided to select papers on the basis of "extended abstracts". It is true that the term has 
been variously interpreted. However, the reasons for this decision were threefold: We still feel that the scientific content and also the originality of a conference contribution can be well expressed in 2000 words. As to clarity of exposition, another often used criterion for selection, if somebody cannot make himself or herself clear in writing in 2000 words, there is little hope that he or she can do so in 4000 or even 6000 words for a conference presentation. The second reason is that the time schedule of the entire selection procedure is such that detailed comments on the manuscript cannot be given anyway. The decision is binary: the contribution is or is not accepted. The amount of feedback on the actual text is very limited and has always been so. Finally, not pinning down authors on their original text almost a year ahead of time gives them the additional freedom to update their contribution with newer and possibly better material.

Let me give you some statistics on this conference. A total number of 799 extended abstracts was submitted: About 50 for the "architecture" track and 250 for each of the others. Of these almost 800 submissions, about 600 were finally accepted as a result of the decisions made by the four program chairmen, based on general rules laid down by our general program chairman. We have moreover given an equal quality status to platform and poster presentations. After all, the main impact of a conference like this is predominantly in a personal exchange of ideas, for which a poster presentation often provides better conditions. The instructions as formulated by our general program chairman were to assign an accepted paper to one of the two categories (platform or poster), depending on the subject of the paper. Poster presentations were not treated as second class contributions.

Continuing with statistics: Our best estimate of the number of participants in this conference is now 655. The eight tutorials organized on Saturday and Sunday attracted 161 participants. Finally, this is the first time that the Proceedings of an ICPR are published in four volumes, totalling 2518 technical pages, that is, disregarding frills such as four times repeated welcome messages and author indexes.

The general conference schedule is as follows: Each afternoon there is a poster session for one of the four specialty conferences. At that time that particular track has no platform presentations. The details of these arrangements may be found in the conference program. It is our hope that in this way we have created favourable conditions for you to communicate with your colleagues. And please remember that, whereas we as an Organizing Committee have done our best to create these conditions, it is you as contributors and participants who in the end will make this conference what it should be: A place for the free exchange of scientific ideas in an atmosphere of mutual understanding and respect.

With the expression of our hope that you will enjoy the scientific as well as the social part of this conference in that spirit, I now officially declare the 11th ICPR to be opened. 